TI 2011-079/3

Tinbergen Institute Discussion Paper

\title{
Is the Service Quality of Private Roads too Low, too High, or just Right when Firms compete Stackelberg in Capacity?
}

Vincent A.C. van den Berg

Erik T. Verhoef 
Tinbergen Institute is the graduate school and research institute in economics of Erasmus University Rotterdam, the University of Amsterdam and VU University Amsterdam.

More TI discussion papers can be downloaded at http://www.tinbergen.nl

Tinbergen Institute has two locations:

Tinbergen Institute Amsterdam

Gustav Mahlerplein 117

1082 MS Amsterdam

The Netherlands

Tel.: +31(0)205251600

Tinbergen Institute Rotterdam

Burg. Oudlaan 50

3062 PA Rotterdam

The Netherlands

Tel.: +31(0)10 4088900

Fax: +31(0)104089031

Duisenberg school of finance is a collaboration of the Dutch financial sector and universities, with the ambition to support innovative research and offer top quality academic education in core areas of finance.

DSF research papers can be downloaded at: http://www.dsf.nl/

Duisenberg school of finance

Gustav Mahlerplein 117

1082 MS Amsterdam

The Netherlands

Tel.: +31(0)20 5258579 


\title{
Is the service quality of private roads too low, too high, or just right when firms compete Stackelberg in capacity?
}

\author{
Vincent A.C. van den Berg, ${ }^{\text {a, }}$, Erik T. Verhoef ${ }^{\text {a,b,\# }}$ \\ a: Department of Spatial Economics, VU University, De Boelelaan 1105, 1081HV Amsterdam, The Netherlands \\ b: Affiliated with the Tinbergen Institute, Roetersstraat 31, 1018 WB Amsterdam, The Netherlands. \\ \#: Email: e.t.verhoef@vu.nl \\ *: Corresponding author: \\ email: v.a.c.vanden.berg@vu.nl, \\ tel: +31 205986049 , \\ fax: +31205986004
}

Version of 13 May 2011

\begin{abstract}
We study road supply by competing firms between a single origin and destination. In previous studies, firms simultaneously set their tolls and capacities while taking the actions of the others as given in a Nash fashion. Then, under some widely used technical assumptions, firms set a volume/capacity ratio that is socially optimal, and thus the level of travel time or service quality is socially optimal. We find that this result does not hold if capacity and toll setting take place in separate stages, as then firms want to limit the toll competition by setting lower capacities; or when firms set capacities one after another in a Stackelberg fashion, as then firms want to limit their competitors' capacities by setting higher capacities. In our Stackelberg competition, the firms that act last have few if any capacity decisions to influence. Hence, they are more concerned with the toll-competition substage, and set a higher volume/capacity ratio than socially optimal. The firms that act first care more about their competitors' capacities that they can influence: they set a lower volume/capacity ratio. So the first firms to enter have a too short travel time from a social perspective, and the last firms a too long travel time. The average private travel time is shorter than socially optimal. Still, in our numerical model, for three or more firms, welfare is higher under Stackelberg competition than under Nash competition, because of the larger total capacity and lower tolls.
\end{abstract}

JEL codes: D62; L13; R41; R42; R48

Keywords: Private Road Supply, Oligopoly, Nash Competition, Stackelberg Competition, Service Quality, Volume/Capacity ratio, Traffic Congestion, Congestion Pricing

\section{Introduction}

As government budgets become increasingly tight, it becomes ever harder to find funds for public road expansion in the face of ever-growing congestion on urban and inter-urban infrastructures. This has sparked a rising interest in private supply of road capacity. In addition, there is a widespread view that private firms operate more efficiently because of their profit motive, thereby lowering the cost of capacity. Finally, private roads may offer a way to introduce congestion-externality tolling in the face of strong public opposition to tolling of existing public roads. In Western Europe, about a third of the highway network is currently privately owned (Verhoef, 2007). In the USA, private roads and express-lanes are becoming increasingly common; the same is true for many developing countries. Hence, private roads form an important and relevant option in contemporary transport policy.

Yet, there are also disadvantages to private road supply. The private-road operator invariably has market power: it is after all impossible to have an infinite number of private roads in parallel to ensure a perfectly-competitive outcome. Hence, firms can set tolls and capacities that might be profit-maximising, but that are not socially optimal. An important question is how harmful this is to social welfare, and to which extend this depends on the number of firms. More generally, the private supply of roads raises questions on the social desirability of market equilibria, and how best to intervene if outcomes are inefficient.

The early literature on private roads looked at toll setting by a monopolist on a road of given capacity. Unless demand is perfectly elastic, the monopolist generally sets a higher toll 
than socially optimally and consequently has less congestion and shorter travel times (see, e.g., Buchanan, 1956; Mohring 1985; and de Palma and Lindsey, 2000). ${ }^{1}$

But this argument ignores capacity setting. Xiao, Yang and Han (2007) study private firms building and operating parallel roads between a single origin and destination. Firms simultaneously determine capacity and tolls while taking the actions of the other as given: i.e. there is a single Nash-competition stage (also called an open-loop game in the literature). Now, firms set the socially-optimal volume/capacity ratio (i.e. they set the optimal service quality) and hence have the same travel time as in the first-best public case. Thus, private supply does not lead to a distorted choice of the service quality. Still, firms do set higher tolls, build lower capacities, and have fewer users than is socially optimal. $\mathrm{Wu}$, Yin and Yang (2011) find that the constant ratio result also holds in a general network. These results are conditional on neutral scale economies characterising road building, and travel time being homogeneous to the degree zero in volume and capacity. The latter condition means that if both the number of cars and capacity double, travel time remains the same, and travel time only depends on the volume/capacity ratio.

The crucial assumption behind the above results is that capacities and tolls are set simultaneously. De Borger and Van Dender (2006) use separate Nash-competition substages for capacity and toll (i.e. two-substages Nash, or a closed-loop game). Now, firms set a lower capacity and a higher volume/capacity ratio (or alternatively a lower service quality), as this lessens toll competition and increases equilibrium tolls. This is opposite to the result in the earlier literature that only looked at toll setting.

Separate stages for capacity and toll seem more realistic, as it takes a considerable time to build or expand a road whereas the toll could be changed at virtually any moment. However, this two substages set-up still assumes that all firms build their roads simultaneously. This also seems unrealistic. Obviously, in reality, not all toll roads were built at the same moment. And if firms play a sequential capacity game, "earlier" movers are unlikely to take the actions of "later" movers as given, and the firms will not compete in a Nash fashion.

To take this into account, we consider firms first setting their capacities sequentially in a Stackelberg fashion, and then simultaneously setting tolls in a Nash fashion. Nash setting of tolls seems most realistic, as tolls can be changed frequently and it is hard to credibly commit to a toll level. ${ }^{2}$ By setting a larger capacity, a firm can induce firms that follow to set lower capacities, which increases its market power and profit. Accordingly, the first few firms to enter set a higher capacity than they would without these strategic considerations, and this means that their volume/capacity ratios are lower than social optimal (or alternatively that their service qualities are higher). The mechanism of De Borger and Van Dender (2006), that they want to set a higher ratio to lessen the toll competition, still occur; but, for these first firms this is dominated by the capacity effect. The last few firms to enter have few if any competitors' capacities to affect. Hence, they care more about the toll substage, and set a higher ratio. In our numerical model, with two firms, the first firm has a lower ratio than socially optimal; the second has a higher ratio. With five firms, the first three firms have a higher ratio and the last two a lower. The net result is that the average volume/capacity ratio on the private roads is lower than socially optimal, and hence average travel time is too short.

Our analysis concerns road transport, but also has implications for rail transport, airlines, airports, and seaports; as well as for non-transport infrastructure such as waste disposal and telecommunication. For instance, there is an extensive literature on airlines competing in different market structures (see, e.g., Daniel, 1995; Breuckner, 2002; Breuckner and Verhoef,

\footnotetext{
${ }^{1}$ These studies assume that users have identical values of time, and we will follow this assumption. Edelson (1971) and Mills (1981) show that with heterogeneous users, the monopolist may charge a lower toll than social optimal.

2 A firm might make a contract with the government or a consumer organisation. But it seems unlikely that these partners would sue for breach of contract when the firm lowers its toll, making this commitment not credible.
} 
2010). Zhang and Zhang (2006) study a monopolist airport's choice of capacity and landing fare while carriers have market power, and find that it sets a lower volume/capacity ratio than socially optimal. Basso and Zhang (2007) extend this with two airports competing single- or two-substages-Nash. Also in these settings, our Stackelberg-capacity game could be applied.

\section{Analytics}

\subsection{Basic policies}

Consider a case where there are multiple roads connecting a single origin and destination. All roads have the same congestion technology and free-flow travel time. Generalised user cost, $c^{i}$, of link $i$ (or user cost for brevity) is homogeneous to the degree zero in the number of users, $q^{i}$, and capacity, $s^{i}$. Hence, user cost, marginal external cost, and travel time only depend on the volume/capacity ratio $q^{i} / s^{i}$. The derivative of user cost with respect to the number of users is always positive; to capacity it is always negative. Capacity costs are proportional to capacity and follow $C^{s, i}=k \cdot s^{i}$. Throughout the paper, we assume that demand is price sensitive and all roads are congestible. We indicate total capacity by $S$, and total number of users by $Q$.

We first discuss some basic policies that act as benchmarks for the oligopolies. Since these policies are conventional in the economic literature, we will keep the discussion short; for a more detailed discussions please see, among others, Small and Verhoef (2007).

In the first-best $(\mathrm{FB})$ case, the toll, $\tau^{F B}$, equals the marginal externality, and capacity is set so that the marginal cost of capacity expansion, $k$, equals the reduction in total user cost, $-c_{S} \cdot Q$, it achieves:

$$
\begin{aligned}
& \tau^{F B}=c_{Q} \cdot Q, \\
& k=-c_{S} \cdot Q .
\end{aligned}
$$

Here, subscripts indicate partial derivatives; superscripts indicate the situation or road. So, $c_{Q}$ is the derivative of user cost to the number of users $Q$.

If a certain initial capacity, $s^{0}$, remains untolled while the new public capacity, $s^{1}$, can be tolled, we are in a second-best (SB) situation, as considered earlier by, for example, Marchand (1968) and Lévy-Lambert (1968). The SB toll has a term that equals the externality on the tolled road, $c_{q^{1}} \cdot q^{1}$, and a negative term to attract users away from the untolled road: ${ }^{3}$

$$
\tau^{S B}=c_{q^{1}} \cdot q^{1}-c_{q^{0}}^{0} \cdot q^{0} \cdot\left(\frac{-D_{Q}}{c_{q^{0}}^{0}-D_{Q}}\right) .
$$

The $D_{Q}$ is the derivative of inverse demand to the total number of users, and $q^{0}$ and $q^{1}$ are the number of users on the initial and new road. While the toll rule is adapted to reflect the second-best distortion, the capacity rule remains (basically) the same: the cost of a marginal capacity expansion equals the user cost reduction on the priced link this achieves:

$$
k=-c_{s^{1}}^{1} \cdot q^{1} .
$$

Due to the assumptions that $c^{i}$ is homogeneous to the degree zero in $q^{i}$ and $s^{i}$ and that $c_{q^{i}}^{i}>0$ and $c_{s^{i}}^{i}<0$, the $c_{s^{i}}^{i} \cdot q^{i}$ and $c_{S} \cdot Q$ only depend on the volume/capacity ratio (respectively, $q^{i} / s^{i}$ and $Q / S$ ). Since $c_{S^{1}}^{1} \cdot q^{1}$ in (4) and $c_{S} \cdot Q$ in (2) both equal $k$, this implies that the volume/capacity ratio must be the same on the tolled SB link and the entire FB network. But since there also is the untolled road, the average ratio for the entire SB network is higher.

\footnotetext{
${ }^{3}$ The second term in (3) is negative since $D_{Q}$ is negative while all other variables are positive.
} 
Also a single firm (SF) offering capacity in parallel to an untolled road uses capacity rule (4), and hence has the same volume/capacity ratio on its road (see also Verhoef and Small, 2007). Any decrease in user costs can be converted into toll payments, so, for a given number of users, it is profit maximising to minimise social cost by using the same capacity rule as in the SB case. But the toll of the single firm is higher, as, following (5), the firm adds a markup to the congestion-externality charge as long as demand is not perfectly elastic (i.e. $-D_{Q}>0$ ) and as long as the untolled road is congestible (i.e. $\left.c_{q^{0}}^{0}>0\right) .{ }^{4}$ The firm internalises the congestion externality, because again any reduction in user cost can be met by a toll increase. The capacities in the single-firm and second-best cases are generally different: the higher private toll means that there are fewer users, which given that the volume/capacity ratios are same means that the capacity of the single firm is lower. Concluding, volume/capacity ratio of the single firm is socially optimal, whereas the choice of toll is distorted by market power.

$$
\tau^{S F}=c_{q^{1}} \cdot q^{1}+q^{0} \cdot c_{q^{0}}^{0} \cdot\left(\frac{-D_{Q}}{c_{q^{0}}^{0}-D_{Q}}\right),
$$

We also look at an untolled road with parallel private firms in perfect competition. This perfect competition (PC) case is equivalent to welfare maximisation under a zero-profit constraint (see Verhoef, 2008). The corresponding Lagrangian is

$$
\Lambda^{P C}=\int_{0}^{Q} D[n] d n-q^{0} \cdot c^{0}-q^{1} \cdot c^{1}-k \cdot s^{1}+\lambda^{0}\left(D[Q]-c^{0}\right)+\lambda^{1}\left(D[Q]-c^{1}-\tau^{1}\right)+\lambda^{P}\left(\tau^{1} \cdot q^{1}-k \cdot s^{1}\right) .
$$

Note that $s^{l}$ is the total capacity of the atomistic firms, and $\tau^{l}$ is their toll. To find the capacity rule, we only need the first order conditions for toll and capacity:

$$
\begin{aligned}
& \partial \Lambda^{\mathrm{PC}} / \partial \tau^{1}=0=-\lambda^{1}+q^{1} \lambda^{P}, \\
& \partial \Lambda^{\mathrm{PC}} / \partial s^{1}=0=-q^{1} \cdot c_{s^{1}}^{1}-k-\lambda^{1} \cdot c_{s^{1}}^{1}-k \cdot \lambda^{P} .
\end{aligned}
$$

Eq. (6a) implies $\lambda^{1}=q \cdot \lambda^{p}$, and inserting this into (6b) results in the capacity rule:

$$
k=-c_{s^{1}}^{1} \cdot q^{1}
$$

Thus, the volume/capacity ratio is again the socially optimal one. Interestingly, the toll follows the same formula as the first-best toll:

$$
\tau^{P C}=c_{q^{1}} \cdot q^{1}
$$

The intuition behind this result follows the self-financing (i.e. zero-profit) result of Mohring and Harwitz (1962) with FB pricing. Since, the volume/capacity ratio is the same as with FB pricing, the FB toll rule also leads to zero profit with perfect competition; and zero profit is what will result from perfect competition. Eq. (8) also implies that the levels of the perfectlycompetitive and first-best toll are the same. The congestion externality is only a function of the volume/capacity ratio. Thus, if the first-best and perfectly-competitive volume/capacity ratios are equal, the tolls — which equal the marginal externalities — will also be equal.

With price-sensitive demand and congestible capacity, the perfectly competitive outcome has a higher toll than the SB case, and thus there are fewer users and capacity is lower. At the same time, the competition drives the perfectly-competitive toll below that of a single firm.

\footnotetext{
${ }^{4}$ Conversely, in Knight (1924) and Edelson (1971), the firm does not add a mark-up because these authors assume $c_{q^{0}}^{0}=0$.
} 


\subsection{Single-stage Nash}

For all our oligopolistic regimes, we assume that the initial capacity remains untolled, and this will limit the market power of the firms. This set-up seems realistic for many practical cases - and of course, when it is not, we are free to set the initial capacity at zero. In other words, zero unpriced capacity is just a special case of our model.

Our first oligopolistic market structure is the single-stage Nash game from Xiao et al. (2007). Firms set their capacities and tolls simultaneously. If firms take the tolls and capacities of the others as given, they set the socially-optimal volume/capacity ratio. At this ratio, the capacity cost of a marginal capacity expansion equals the user cost reduction on this link it causes. If the firm offered a higher capacity this would reduce user costs and it could ask a higher toll, but then the extra revenue would be smaller than the extra capacity costs. Note that firms actually choose their capacity, but since there is complete information this is equivalent to choosing the volume/capacity ratio.

Tolls are higher than with perfect competition as firms have market power, and this also means that total number of users and capacity are lower. Yet, as DeVany and Saving (1980) and Engel, Fisher and Galetovic (2004) show for a given capacity, as the number of firms increases, the equilibrium toll decreases and approaches the perfectly-competitive toll. Moreover, as the number of firms increases, total capacity also approaches the perfectlycompetitive one.

\subsection{Two-substages Nash}

In the two-substages Nash set-up of De Borger and Van Dender (2006), the capacity setting precedes the toll setting. In each substage, firms take the actions of the others in that substage as given. Firms have an incentive to set a lower capacity, as this lessens toll competition and increases Nash-equilibrium tolls: the lower total capacity is, the higher the toll a firm can set due to the higher congestion on the competitors' roads. This alteration of the capacity rule means that firms set a higher volume/capacity ratio than is socially optimal.

Using the formulas of De Borger and Van Dender (2006), we can write the capacity rule for a duopoly as

$$
k+\text { Stategic effect }=k-q^{i} \cdot \frac{\partial \tau^{i, *}}{\partial s^{i}}=-c_{s^{i}}^{i} \cdot q^{i},
$$

where superscript ${ }^{*}$ indicates that the toll is determined by the Nash toll-setting substage. Our model assumes that the outcome is symmetric in capacities. De Borger and Van Dender (2006) find that, for their linear congestion technology and with very low marginal costs of capacity ( 0.25 or lower, where their base case cost is 1$)$, an asymmetric equilibrium would result, which has slightly different characteristics. Still, even then, the volume/capacity ratios and tolls are higher than with single-stage Nash. We use the "Bureau of Public Roads" (BPR) function of travel time, and have only encountered symmetric outcomes in our numerical models, even for a marginal capacity cost as low as 0.05 where our base-case cost is $7 .^{5}$ Therefore, we focus on the symmetric outcome.

\subsection{Stackelberg}

In our Stackelberg game, firms set their capacities one after the other. Then the toll setting substage follows, in which tolls are set in a Nash fashion. The first firm to act is the leader

\footnotetext{
${ }^{5}$ An advantage of the symmetric outcome is that in the analysis of De Borger and Van Dender (2006), it ensures that the response function of firm $i$ 's capacity to firms $j$ 's is negative; with asymmetry this need not be so. We assume that capacity costs are high enough to ensure downward-sloping response functions. In our numerical analyses, we have only encountered such downward-sloping functions, but our solution method does not assume this.
} 
and has the best position. With its capacity, it influences the capacity setting of all other firms, as well as the toll substage. By setting a higher capacity, the leader limits the capacities chosen by the other firms, which raising its market power. Hence, the capacity rule is different than in the fully-competitive case, and the leader's volume/capacity ratio is lower than socially optimal. Still, this lower ratio also has a profit lowering effect: given the actions of the others, it would be profit maximising to set the socially-optimal ratio. Optimal capacity is found when, for a marginal capacity increase, the profit increasing effect from the induced lower capacities of the competitors plus that of the lower user cost equals the profit lowering effects from the stronger competition in the toll-setting substage and higher capacity cost.

If there are many firms acting sequentially, the second firm to act also has an incentive to set a lower volume/capacity ratio than is socially optimal. However, its ratio will be above that of the first firm, as it has fewer capacity decisions to influence. The last firm to act has no capacities to influence. So it is only concerned with the toll setting substage. Just as in De Borger and Van Dender's (2006) two-substages Nash game, this firm sets a lower ratio to lessen the toll competition and raise the Nash-equilibrium tolls.

Since the firms set different volume/capacity ratios, their travel times are different. Since the sum of user cost and toll (i.e. the generalised price, or price for brevity) must be the same on all roads, the first firm - that has the shortest travel time - can ask the highest toll. The last firm has the longest travel time and lowest toll.

\subsection{Sequential entry}

Our last oligopolistic market structure follows Verhoef (2008) and is sequential entry. This set-up is in between the two-substages-Nash and Stackelberg set-ups. There are again separate substages for capacity and toll. When the first firm enters, it first sets its capacity and then toll, assuming that it is and will remain the only firm. Since there are no other players to influence, it is profit maximising to have the socially optimal volume/capacity ratio. Then, a second firm enters, and optimises its capacity given that there are two firms and anticipating the toll-competition in the Nash substage. The capacity of the first firm is fixed, but it can change its toll. ${ }^{6}$ The second firm's capacity influences the toll of the first firm, and this alters its capacity-setting rule, resulting in the second firm setting a higher volume/capacity ratio. Each further entry follows the same pattern as for two firms.

The sequential entry set-up might seem inconsistent in that firms are forward-looking to the toll substage, but are continuously surprised when further entry occurs (i.e. they are myopic to the next capacity stage). Yet, it also seems plausible that firms do not perfectly know what the future will bring and optimise given the current situation. Then a remark could be made against the Nash and Stackelberg games, in which a firm has to known how many firms there will be. In reality, the market structure might be a mix of our Stackelberg and sequential-entry games: i.e. a firm does not know how many firms there will be, but has a prior belief about the likelihood of each outcome, and optimises given this belief.

\section{Numerical model}

We use a numerical model to obtain insights into the relative performance of the schemes identified above. The calibration of our model follows Verhoef $(2007 ; 2008)$. The model is simple, but it is calibrated to represent a realistic congested peak-hour highway. User cost follows the BPR function, just as in most of the recent literature on private roads:

\footnotetext{
${ }^{6}$ This is not as restrictive as it seems. The first firm would like decrease its capacity, but this is not directly possible and would certainly not result in its recuperating all capacity costs. Hence, the best it can do is to keep its current capacity.
} 


$$
c^{i}\left[q^{i} / s^{i}\right]=\alpha \cdot t_{f}\left(1+0.15\left(\frac{q^{i}}{s^{i}}\right)^{4}\right) .
$$

Free-flow travel time, $t^{f}$, is half an hour. Using a free-flow speed of $120 \mathrm{~km} / \mathrm{hour}$, this implies a trip length of 60 kilometres. The value of time, $\alpha$, is 7.5. Units of capacity are set so that a traffic lane corresponds to a capacity of $s^{i}=1500$. Capacity costs follow $C^{s, i}=k \cdot s^{i}$, where $k$ equals 7. Since our unit of time is an hour, $k$ is the hourly capacity cost. See Verhoef (2008, pp. 476-477) for the derivation of $k=7$ from the average yearly capital cost of $€ 5$ million per lane-km or $\$ 8$ million per lane-mile for freeways in the Netherlands. This cost seems in line with the estimates for the USA. Washington State Department of Transport (2005) reports 15 project from outside the state and 21 from inside the state. For outside the state, median cost is about $\$ 8$ million per lane-mile while a third is above $\$ 10$ million. For in the state, median cost is around $\$ 5$ million while a quarter is above $\$ 10$ million.

All roads have the same congestion and construction technologies and free-flow travel time. The initial capacity in the base equilibrium is $s^{0}=1500$. Inverse demand follows

$$
D[Q]=A-B \cdot Q
$$

The $A$ equals 61.27 and $B 0.0117$. In the base equilibrium, the price elasticity is -0.5 . This calibration results in a very congested road in the base case, with a travel time that is 5.4 times the free-flow one. If the initial situation were less congested, the gain of private road supply and public policies would be lower. We choose this rather extreme level of initial capacity to allow a fair number of firms to enter in all regimes (even though we do not impose a minimum road size for an entering firm).

\subsection{Basic policies and Nash capacity competition}

Table 1 describes the benchmark equilibria. It shows such performance measures as consumer surplus, welfare (the sum of consumer surplus and system profit), and relative efficiency, which is the welfare gain of a policy from the initial base equilibrium relative to the first-best gain. It also gives the volume/capacity ratio averaged over the entire network, on the untolled part, and on the tolled part. In the base equilibrium, there is no tolling and capacity is 1500 . In the first-best (FB) case, capacity is more than twice as large, and the toll equals the marginal congestion externality.

In the second-best (SB) case, the initial capacity remains untolled, but the new capacity has a welfare-maximising toll. Optimal capacity is higher than in the first-best case, but the volume/capacity ratio on the tolled part is the same. Due to the low initial capacity, the welfare gain of the second-best option is very close to the FB gain. With more initial capacity, the relative efficiency would be lower: the capacity expansion would be less important, while the detrimental effect of the larger untolled capacity would be larger. The SB set-up makes a large loss, and the government has to finance this from other sources. This might be difficult in practice, and may lead to tax distortions elsewhere in the economy (which we ignore).

A single firm building and tolling an extra road is also welfare improving. In fact, private road supply is in our setting always welfare improving: the firm makes a profit; whereas the consumers cannot be worse off (since if users choose to use the private road, it cannot have a higher price than the untolled road). Again, the private road has the same volume/capacity ratio as the first-best network. Still, the price and toll are higher, and capacity is lower.

The final case in Table 1 is perfect competition, which describes what happens when an infinite number of firms add capacity in parallel to the untolled capacity. This outcome is a useful benchmark for the oligopolistic regimes where firms have market power. Note that the perfectly-competitive private operators set the socially-optimal volume/capacity ratio. 


\begin{tabular}{lccccc}
\hline & $\begin{array}{c}\text { Base } \\
\text { equilibrium }\end{array}$ & First-best & Second-best & Single Firm & $\begin{array}{c}\text { Perfect } \\
\text { competition }\end{array}$ \\
\hline Total capacity $(S)$ & 1500 & 3451.8 & 3734.0 & 2078.5 & 2708.7 \\
Total demand $(Q)$ & 3500 & 4331.3 & 4782.7 & 4331.3 & 3927.9 \\
Toll & - & 5.58 & 0.31 & 10.29 & 5.58 \\
Overall $Q / S$ & 2.333 & 1.255 & 1.281 & 1.890 & 1.599 \\
$q^{0} / s^{0}$ on untolled part & 2.333 & - & 1.320 & 2.135 & 1.876 \\
$q^{l} / s^{l}$ on tolled part & - & 1.255 & 1.255 & 1.255 & 1.255 \\
Price & 20.42 & 11.16 & 5.46 & 15.43 & 10.72 \\
$c^{0}$ on untolled part & 20.42 & - & 5.46 & 15.43 & 10.72 \\
$c^{l}$ on tolled part & - & 5.14 & 5.14 & 5.14 & 5.14 \\
System profit & -10500 & 0 & -25266 & -7083 & -10500 \\
Profit tolled part & - & 0 & -14766 & 3417.32 & 0 \\
Consumer surplus & 71484 & 109468 & 133472 & 90029 & 109468 \\
Welfare & 60984 & 109468 & 108206 & 82946 & 98968 \\
Relative efficiency & 0 & 1 & 0.974 & 0.453 & 0.783 \\
\hline
\end{tabular}

Table 2 shows that, with single-stage Nash outcomes for varying number of firms. In all oligopolistic settings, a single firm competing leads to the same outcome as the single firm in Table 1. We only include it again for easy of reference. All firms set their tolls and capacities at the same time. Since the equilibrium is symmetric in that all firms have the same tolls and capacities, we give one set of result for any firm $i$. Because firms take the actions of the others a given, the best they can do is set the socially-optimal volume/capacity ratio.

As the number of firms increases, the single-stage Nash outcome approaches the perfectlycompetitive outcome. With a single firm, the welfare gain is $58 \%$ of that with perfect competition; with two firms, it is already $83 \%$; and with 5 firms, it is $94 \%$ percent. This suggests that a limited number of firms may be enough to obtain an equilibrium that is close to perfect competition in terms of efficiency.

Table 2. Single-stage Nash competition

\begin{tabular}{lccccc}
\hline \multicolumn{1}{c}{ Number of firms } & 1 & 2 & 3 & 4 & 5 \\
\hline Total capacity $(S)$ & 2078.5 & 2411.4 & 2521.4 & 2572.7 & 2602.0 \\
Total demand $(Q)$ & 3928.0 & 4150.5 & 4219.6 & 4250.9 & 4268.6 \\
Average toll & 10.29 & 7.69 & 6.88 & 6.52 & 6.31 \\
Overall $Q / S$ & 1.890 & 1.721 & 1.673 & 1.652 & 1.640 \\
$q^{0} / s^{0}$ on the untolled part & 2.135 & 2.005 & 1.959 & 1.937 & 1.924 \\
$q^{i} / s^{i}$ on each private road & 1.255 & 1.255 & 1.255 & 1.255 & 1.255 \\
Price & 15.43 & 12.83 & 12.03 & 11.66 & 11.46 \\
Profit firm $i$ & 3417.3 & 1206.7 & 557.2 & 315.9 & 202.6 \\
Consumer surplus & 90029 & 100518 & 103892 & 105440 & 106319 \\
Welfare & 82946 & 92432 & 95064 & 96204 & 96832 \\
Relative efficiency & 0.453 & 0.649 & 0.703 & 0.726 & 0.739 \\
Welfare gain relative to & 0.578 & 0.828 & 0.897 & 0.927 & 0.944 \\
perfect competition & & & & & \\
\hline
\end{tabular}

\subsection{Two-substages Nash Competition}

Now we turn to the first of three set-ups where firms set their capacities strategically to influence the actions the other firms. These strategic considerations change the capacity rule, which means that firms have a different volume/capacity ratio than is socially optimal. As Table 3 shows, with two-substages Nash competition, firms have an incentive to set a lower 
capacity and higher ratio, because this lessens toll competition, thereby raising Nashequilibrium tolls. However, this higher ratio comes at a cost for the firm: it raises travel time and this lowers the toll users are willing to pay. The profit-maximising capacity is found where, for a marginal capacity increase, the profit-enhancing effect of the lower user costs equals the detrimental effect of the lower tolls of the competitors and higher capacity cost.

With two firms, the welfare gain of two-substages Nash is much lower than with a single stage, since total capacity is lower and tolls are higher. Yet, as the number of firms increases the advantage for the firms of the separate setting of capacity and toll decreases. Our results indicate that this two-substages Nash game approaches single-stage Nash and perfect competition as the of firms becomes large. This is also logical, if there are many firms, it is hard for a firm to influence the toll setting of others, as it only controls a tiny part of the total capacity. Hence, then the outcome is close to the single-stage Nash, where it is impossible to affect the toll setting of other firms.

Table 3. Two-substages Nash competition

\begin{tabular}{lccccc}
\hline \multicolumn{1}{c}{ Number of firms } & 1 & 2 & 3 & 4 & 5 \\
\hline Total capacity $(S)$ & 2078.5 & 2292.3 & 2404.4 & 2470.2 & 2513.1 \\
Total demand $(Q)$ & 3928.0 & 4087.1 & 4159.9 & 4200.0 & 4225.2 \\
Average toll & 10.29 & 8.27 & 7.44 & 6.99 & 6.72 \\
Overall $Q / S$ & 1.890 & 1.966 & 1.815 & 1.747 & 1.710 \\
$q^{0} / s^{0}$ & 2.135 & 2.044 & 1.999 & 1.972 & 1.955 \\
$q^{i} / s^{i}$ & 1.255 & 1.288 & 1.285 & 1.280 & 1.277 \\
Price & 15.43 & 13.57 & 12.72 & 12.26 & 11.96 \\
Profit firm $i$ & 3417.3 & 1449.6 & 772.1 & 474.1 & 319.2 \\
Consumer surplus & 90029 & 97472 & 100971 & 102931 & 104170 \\
Welfare & 82946 & 89871 & 92787 & 94328 & 95266 \\
Relative efficiency & 0.453 & 0.596 & 0.656 & 0.688 & 0.707 \\
Welfare gain relative & 0.578 & 0.760 & 0.837 & 0.878 & 0.903 \\
to perfect competition & & & & & \\
\hline
\end{tabular}

\subsection{Sequential entry set-up}

The sequential-entry market structure follows Verhoef (2008). Firms again have separate capacity and toll decisions. The difference is that now firms enter sequentially. First, firm 1 enters, and sets its capacity and then its toll, assuming that it will be the only firm. Next, a second firm enters and sets its profit-maximising capacity given that there are two firms while taking into account how this affects the toll-setting substage. So the first firm's capacity is fixed, as this is a long-term decision; while its toll can be changed, as this is a short run decision. The entry pattern is the same for the third and further entrants. Firms are thus forward looking to the toll-setting substage, but myopic to the next entry (i.e. the next capacity stage). The difference with the two-substages Nash is that now firms build their road sequentially, which seems more realistic as not all roads have been build at the same time.

As Table 4 shows, even though all firms have the same cost structures and congestion technologies, they are now ex-post asymmetric. This is due to the sequential decision making. The first firm sets a much higher capacity than it would under single- or two- substages Nash competition, and this limits the capacities that the others will set. Yet, this sequential decision making need not be good for the firms, as becomes clear when comparing the profits shown in Fig. 1 (sequential entry) with those in Table 3 (two-substages Nash). For 4 or more firms, firm 1's profit is lower with sequential entry than with two-stage Nash. Firm 2 always has a lower profit with sequential entry. Sequential entry leads to a higher total capacity, and thus to stronger toll competition. For the up to 5 firms we study, sequential entry gives a higher welfare gain than Nash competition. 
Table 4. Results under sequential entry

\begin{tabular}{|c|c|c|c|c|c|}
\hline Number of firms & 1 & 2 & 3 & 4 & 5 \\
\hline Total capacity $(S)$ & 2078.5 & 2399.1 & 2576.4 & 2670.3 & 2718.6 \\
\hline Total demand $(Q)$ & 3928.0 & 4138.4 & 4237.3 & 4285.0 & 4308.4 \\
\hline Average toll & 10.29 & 7.86 & 6.80 & 6.30 & 6.05 \\
\hline Overall $Q / S$ & 1.890 & 1.725 & 1.645 & 1.605 & 1.585 \\
\hline$q^{0} / s^{0}$ & 2.135 & 2.012 & 1.946 & 1.912 & 1.894 \\
\hline Capacity firm $1\left(s^{l}\right)$ & 578.5 & 578.5 & 578.5 & 578.5 & 578.5 \\
\hline Capacity firm $2\left(s^{2}\right)$ & - & 320.5 & 320.5 & 320.5 & 320.5 \\
\hline Capacity firm $3\left(s^{3}\right)$ & - & - & 177.4 & 177.4 & 177.4 \\
\hline Capacity firm $4\left(s^{4}\right)$ & - & - & - & 93.8 & 93.8 \\
\hline Capacity firm $5\left(s^{5}\right)$ & - & - & - & - & 48.3 \\
\hline Price & 15.43 & 12.98 & 11.82 & 11.26 & 10.99 \\
\hline Consumer surplus & 90029 & 99931 & 104767 & 107138 & 108308 \\
\hline Welfare & 82946 & 91939 & 95687 & 97365 & 98153 \\
\hline Relative efficiency & 0.453 & 0.638 & 0.716 & 0.750 & 0.767 \\
\hline $\begin{array}{l}\text { Welfare gain relative to } \\
\text { perfect competition }\end{array}$ & 0.578 & 0.814 & 0.910 & 0.953 & 0.973 \\
\hline
\end{tabular}

Fig. 1. Firm profit by the number of firms under sequential entry

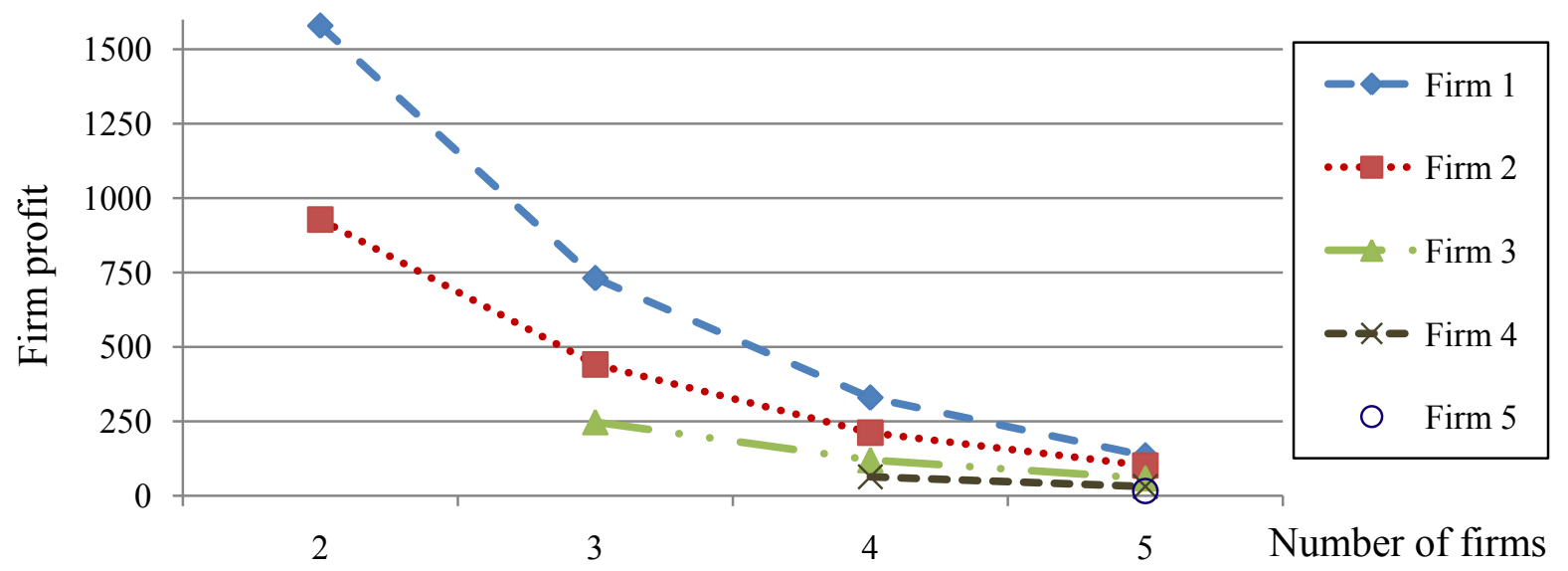

Fig. 2. The toll of each firm by the number of firms under sequential entry

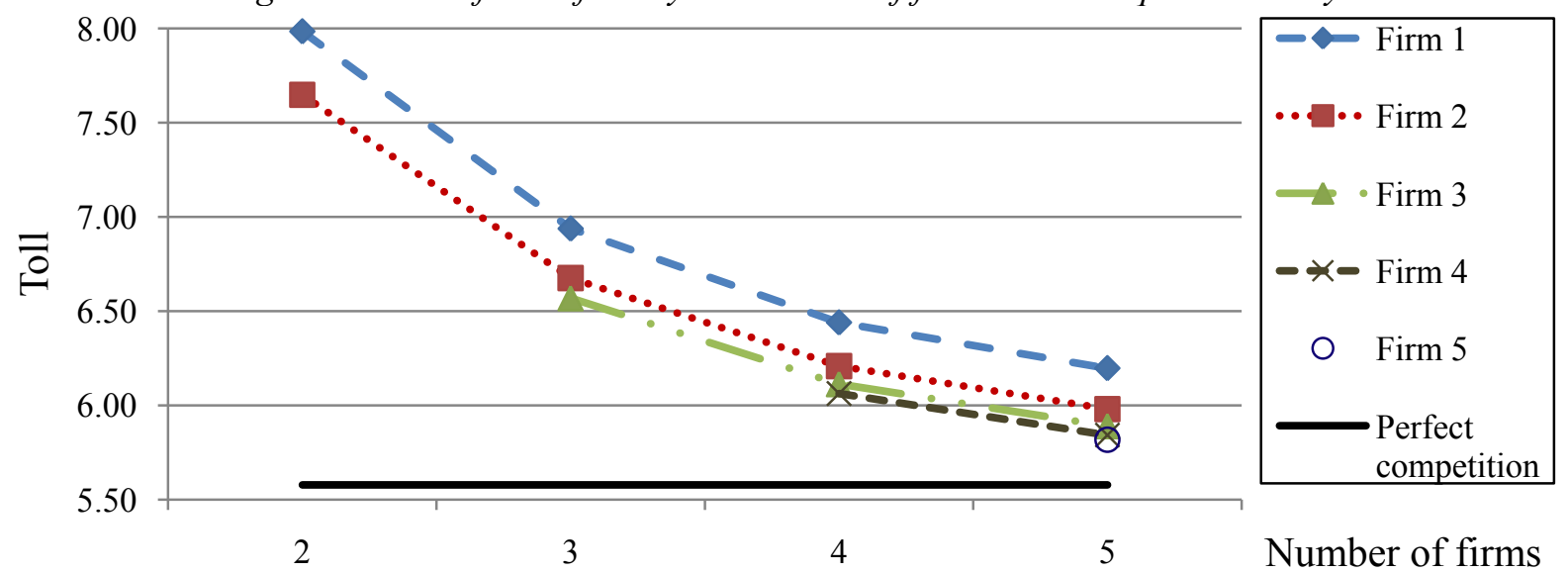

As the number of firms increases, total capacity increases and tolls decrease (see Fig 2), leading to lower profits. Firm 1 always attains the largest profit due to its largest size. The later a firm entered, the lower its profit will be. 
The sequential-entry market structure does not approach perfect competition when the number of firms goes to infinity. With 5 firms, total capacity is already above the perfectlycompetitive level, and the entries of the sixth and seventh firms only increase capacity further (these cases are not shown, but for this game they were calculated). It is perhaps surprising that an above perfectly-competitive capacity level can be profitable. The reason is that, with five firms, a firm still has market power, and adds a mark-up to the toll (see Fig. 2); whereas with perfect competition, the toll equals the congestion externality and the mark-up is zero. At some point, there will be no further entry, as this would decrease market power so much that the entering firm would make a loss. Still, the welfare loss from this game never reaching perfect competition is limited. Two firms entering sequentially gives a consumer surplus that is $9 \%$ lower and welfare gain that is $19 \%$ lower than with prefect competition; for five firms these figures are, respectively, $1 \%$ and $3 \%$.

An intriguing result from the sequential-entry market structure is the development of the volume/capacity ratios in Fig 3. When firm 1 enters, it sets the socially-optimal ratio, since there are no other players to influence. When firm 2 enters, it sets a higher ratio, because this increases Nash-equilibrium tolls, thereby increasing its profit. Because the first capacity is fixed but the new entry attracts users away, the first firm's volume/capacity ratio decreases and is now lower than socially optimal. The average ratio on the private roads also decreases, because firm 1 is larger. For later entries a similar pattern holds: the entrant sets a ratio that is higher than socially optimal to limit the toll competition, and the ratios of the incumbents and the overall ratio decrease.

Fig. 3. Volume capacity ratio under sequential entry

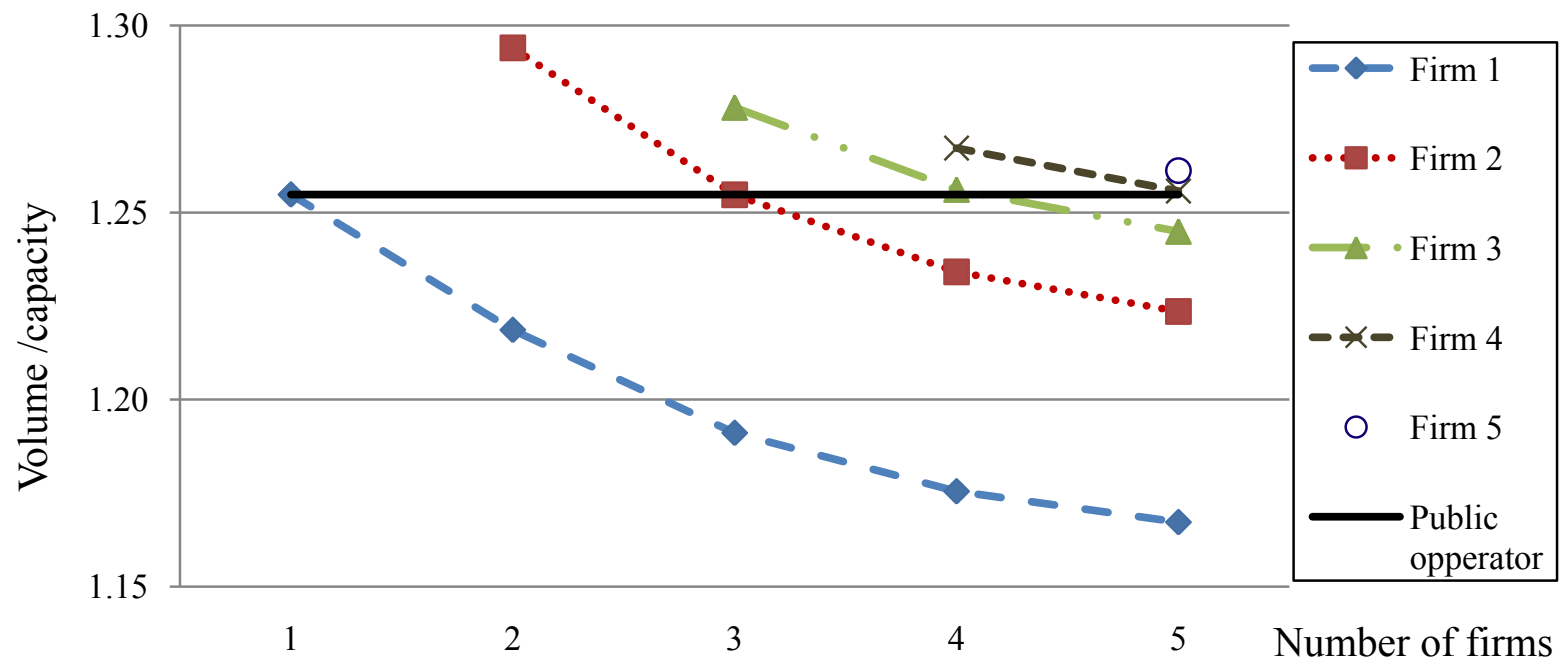

\subsection{Stackelberg capacity competition}

Our last market structure extends the previous one by making firms forward looking in their capacity choices: they recognise that their capacity influences the capacity setting of all following firms as well as the Nash toll-setting substage. The difference with the previous setting is that now firms know how many firms there will be, whereas before they assumed that they were the last entrant. It is important to emphasise that for each number of firms the table and figures give the results after the final stage. Unlike with sequential-entry, the various number of firms should not be interpreted as intermediate stages in the same dynamic process.

Table 5 and Fig. 4 show the results. With two firms, the leader sets a higher capacity and lower volume/capacity ratio than the follower, which means that the leader has more market power and a shorter travel time, allowing it to can ask a higher toll. Still, the leader's capacity is below the one with sequential entry, as this lower capacity lessens toll competition, which 
raises profit even though it also raises the capacity of firm 2. The leader's capacity is well above the single- or two-substages-Nash level. For three or more entrants, the set-up and the results follow the same lines.

Table 5. Results under Stackelberg capacity competition

\begin{tabular}{lccccc}
\hline Number of firms & 1 & 2 & 3 & 4 & 5 \\
\hline Total capacity $(S)$ & 2078.5 & 2397.6 & 2564.2 & 2647.2 & 2686.6 \\
Total demand $(Q)$ & 3928.0 & 4137.8 & 4233.6 & 4279.0 & 4301.2 \\
Average toll & 10.29 & 7.87 & 6.82 & 6.32 & 6.06 \\
Overall $Q / S$ & 1.890 & 1.726 & 1.651 & 1.616 & 1.601 \\
$q^{0} / s^{0}$ & 2.135 & 2.013 & 1.949 & 1.916 & 1.890 \\
Capacity firm $1\left(s^{l}\right)$ & 578.5 & 576.2 & 543.4 & 489.7 & 428.3 \\
Capacity firm 2 $\left(s^{2}\right)$ & - & 321.5 & 336.5 & 350.7 & 345.8 \\
Capacity firm 3 $\left(s^{3}\right)$ & - & - & 184.3 & 201.0 & 226.5 \\
Capacity firm 4 $\left(s^{4}\right)$ & - & - & - & 105.8 & 122. \\
Capacity firm 5 $\left(s^{5}\right)$ & - & - & - & - & 63.2 \\
Price & 15.43 & 12.98 & 11.86 & 11.33 & 11.08 \\
Consumer surplus & 90029 & 99902 & 104580 & 106837 & 107949 \\
Welfare & 82946 & 91916 & 95558 & 97177 & 97943 \\
Relative efficiency & 0.453 & 0.638 & 0.713 & 0.746 & 0.762 \\
Welfare gain relative to & 0.578 & 0.814 & 0.910 & 0.953 & 0.973 \\
perfect competition & & & &
\end{tabular}

Fig. 4. Volume capacity ratio on each road under Stackelberg capacity competition

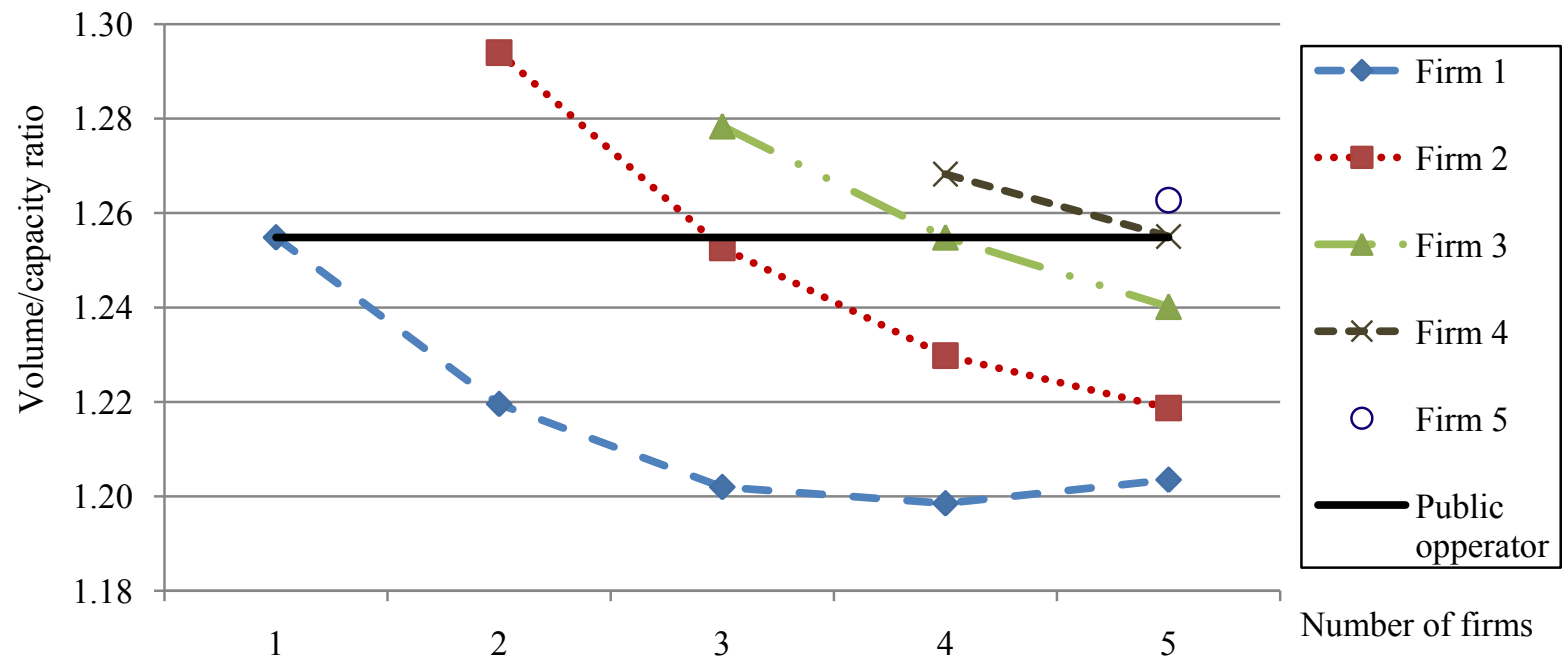

For an end equilibrium with up to 4 firms, the volume/capacity ratio of firm 1 decreases with the number of firms. Yet, with 5 firms, it is higher than with 4 firms. This suggests that, as the number of firms increases even further, the ratios of all firms may approach the socially-optimal ratio. With more firms, it is more difficult to influence the capacity and toll setting of others, and trying this becomes less profitable. Conversely, the profit loss from setting a lower ratio remains, in that the increase in capacity cost is larger than the toll revenue gain due to the lower travel time; while for a higher ratio, the capacity cost reduction is offset by a larger loss in revenue. Only when it is possible to influence the actions of the others is it profitable to set a different ratio, but with many firms, the strategic effect is small. This suggests that our Stackelberg market structure also approaches perfect competition as the number of firms becomes large, just as with standard Stackelberg competition. Certainly, as Figs. 5 and 6 indicate, the tolls and profits approach the perfectly-competitive outcome. 
Fig. 5. The toll of each firm by the final number of firms under Stackelberg competition

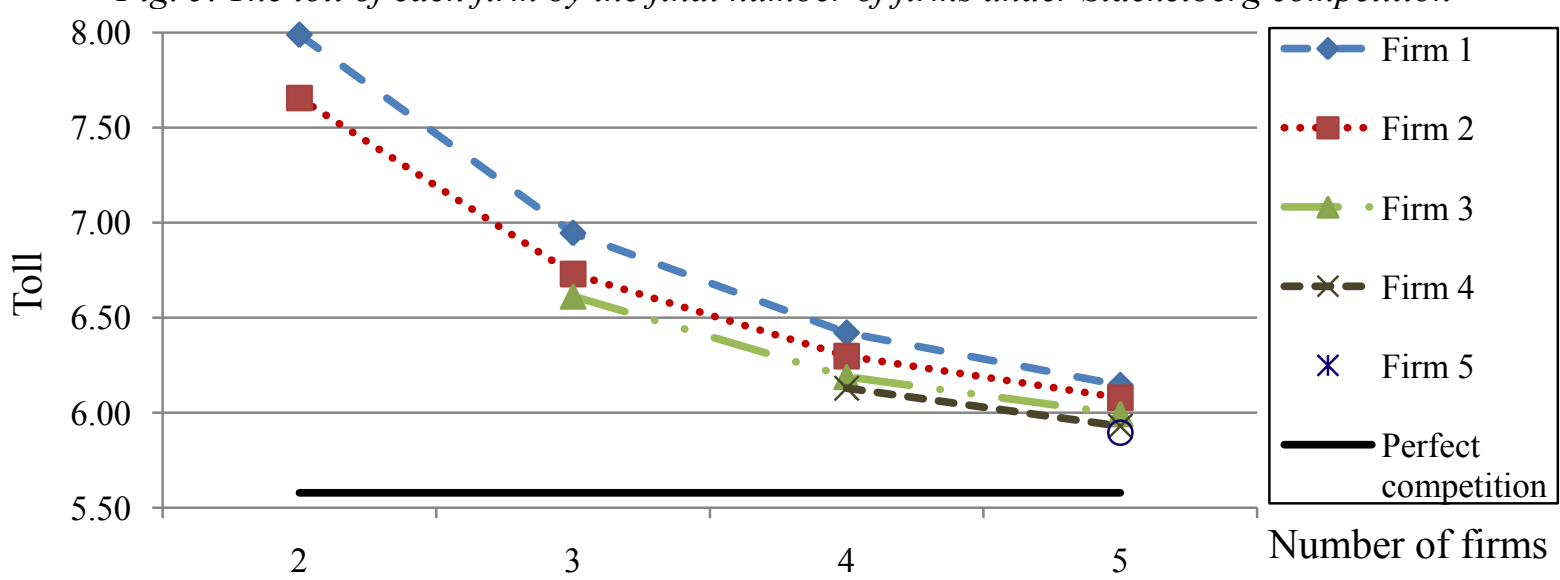

Fig. 6. Firm profit by the final number of firms under Stackelberg competition

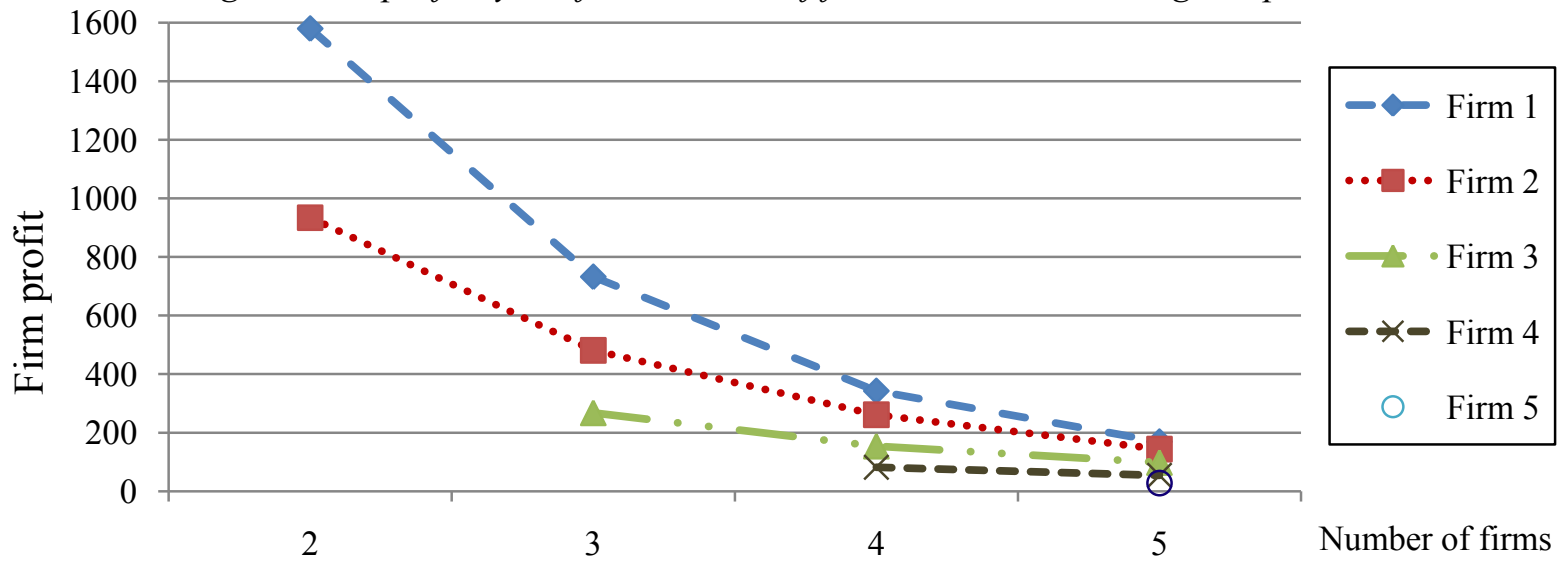

\subsection{Comparison of the oligopolistic market structures}

Fig. 7 compares the average volume/capacity ratio in the different oligopolistic settings. It also shows the ratio with perfect competition (which is the socially optimal one) as a benchmark. Single-stage Nash results in constant private volume/capacity ratios that are socially optimal. When the capacity and toll competitions are separate substages, firms set a higher ratio to lessen the later toll competition. Still, this ratio seems to approach the perfectly-competitive level as the number of firms increases. Conversely, when firms set their capacities one after the other, the average ratio is below the perfectly competitive one. For Stackelberg competition, the average seems to level off at five firms. And we expect, when number of firms becomes even larger, that the average will increase again and approach the perfectly-competitive level: with more firms it becomes ever more difficult to influence your competitors' capacities and tolls, and this makes strategic capacity setting less attractive.

Sequential entry never reaches perfect competition because at some point capacity is so high that no further entry is profitable. Moreover, as Fig. 8 also shows, in our numerical model, the capacity level with 5 firms is already above with perfect competition, and further entry only increases capacity.

Figs. 8 to 10 compare the capacities, average tolls, and relative efficiencies in the different market structures. All set-ups lead to substantial welfare gains that, even for 2 firms, are relatively close to the perfectly-competitive level. Only with a single firm is the relative efficiency much lower with 0.453 . Two-substages Nash attains of all oligopolies the lowest gain, as firms build less capacity and have higher tolls. 
The Stackelberg and sequential entry games have very similar results. A weakness of the Stackelberg model is that firms have to know how many firms there will be with certainty. Conversely, with sequential entry, each firm assumes that it is the last entry, and every firm is "surprised" when a further entry occurs. Both models seem useful benchmarks, and it seems likely that in reality the outcome would be a mix of the two games.

Fig. 7. Weighted average volume/capacity ratio on the private roads

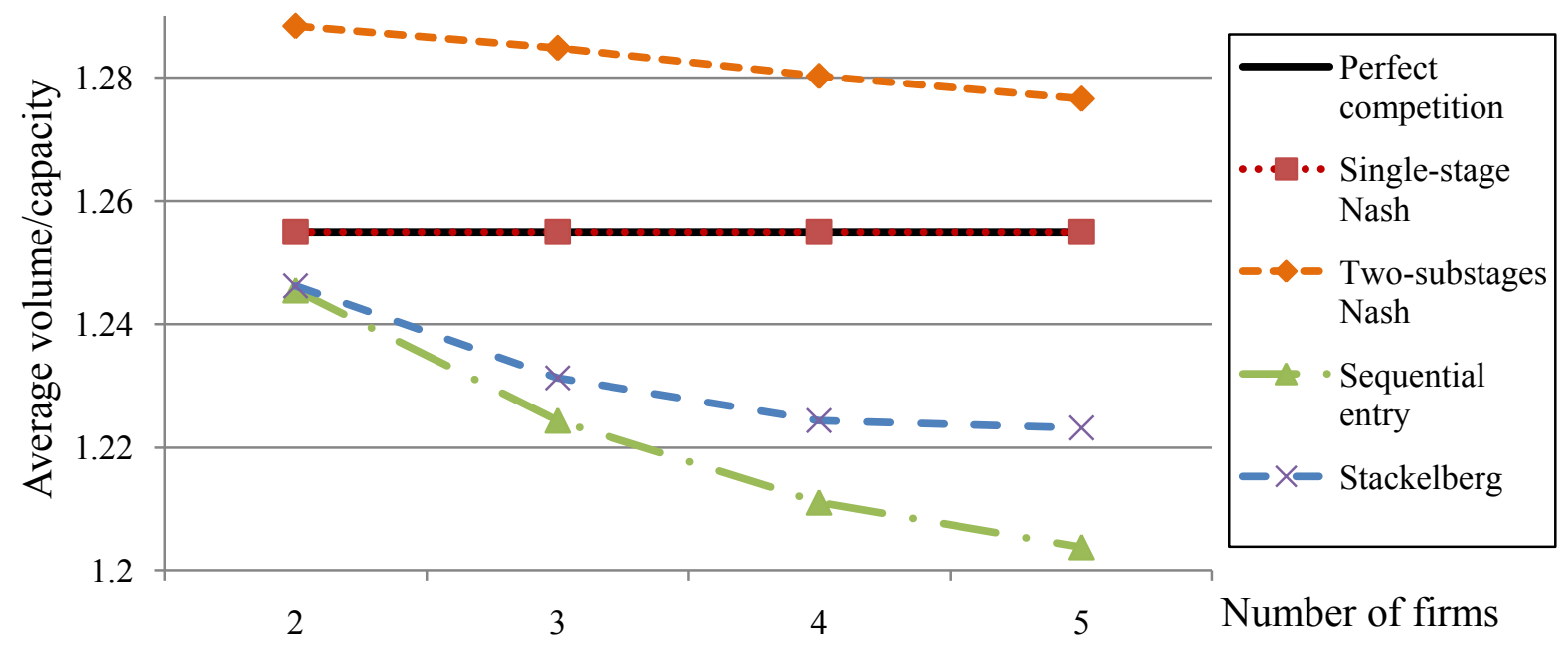

Fig. 8. Total capacity and the number of firms

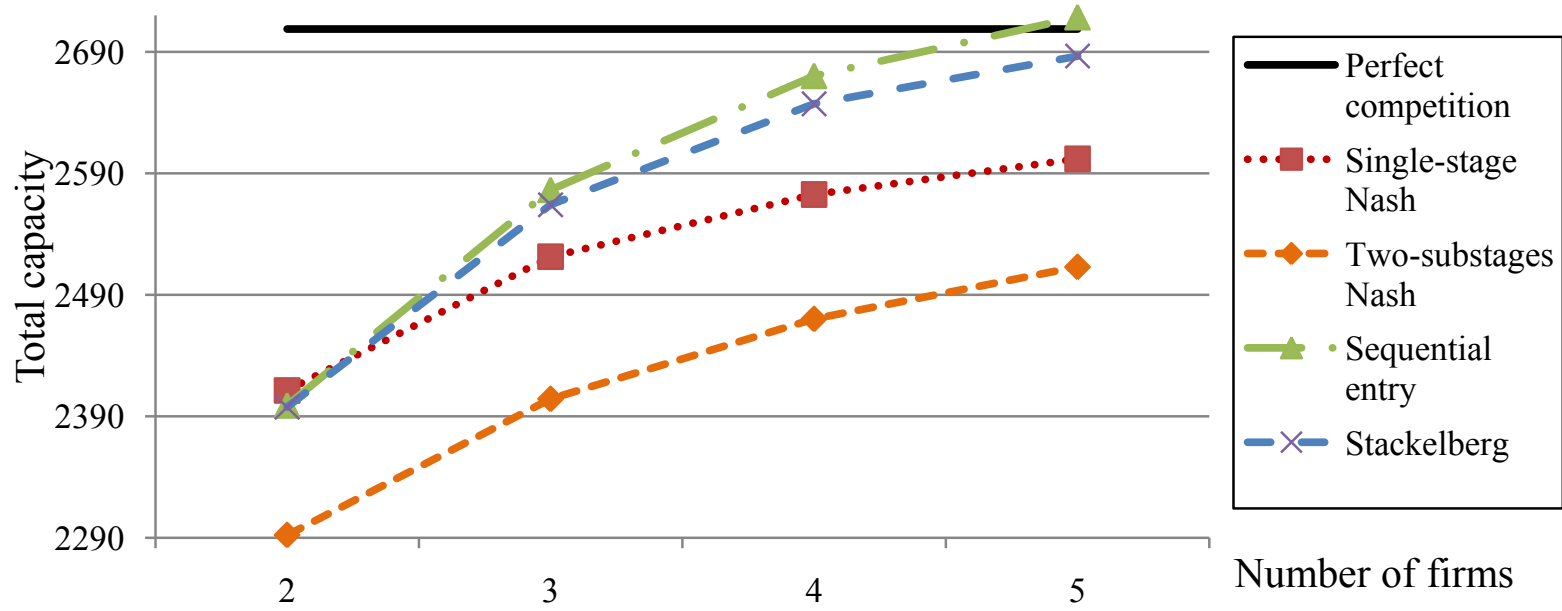

Fig. 9. Weighted average toll and the number of firms

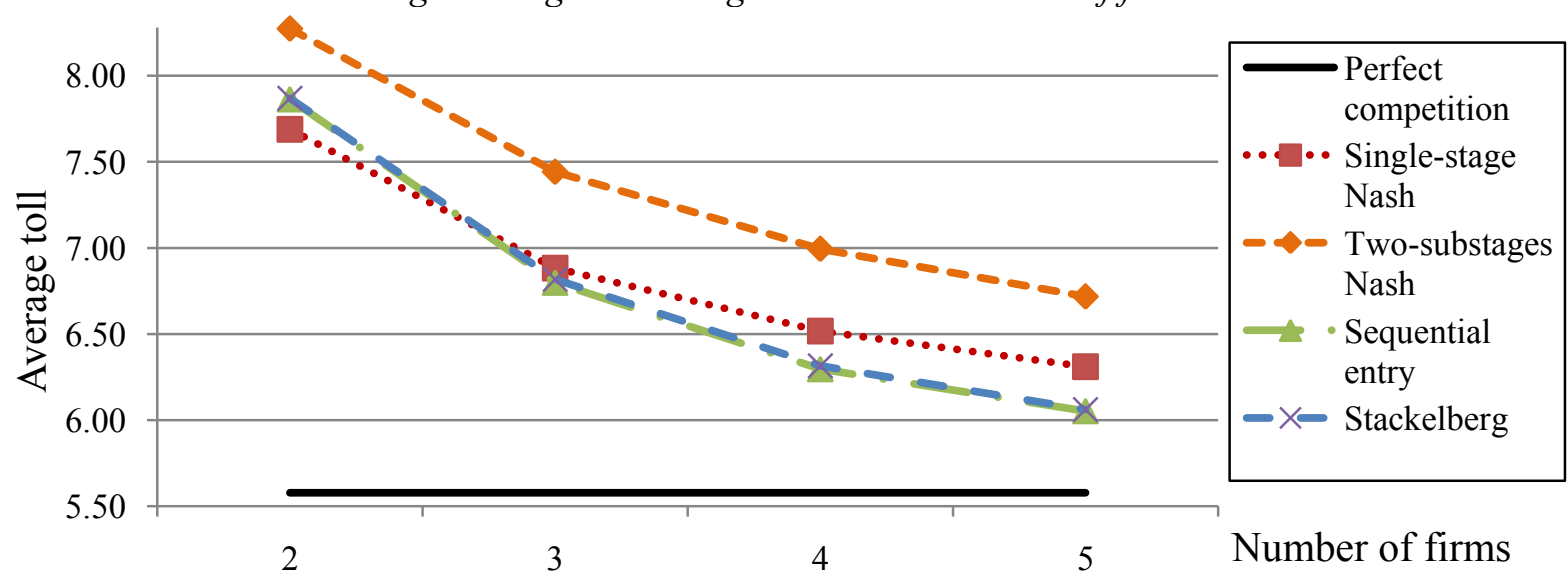


Fig. 10. Relative efficiency and the number of firms

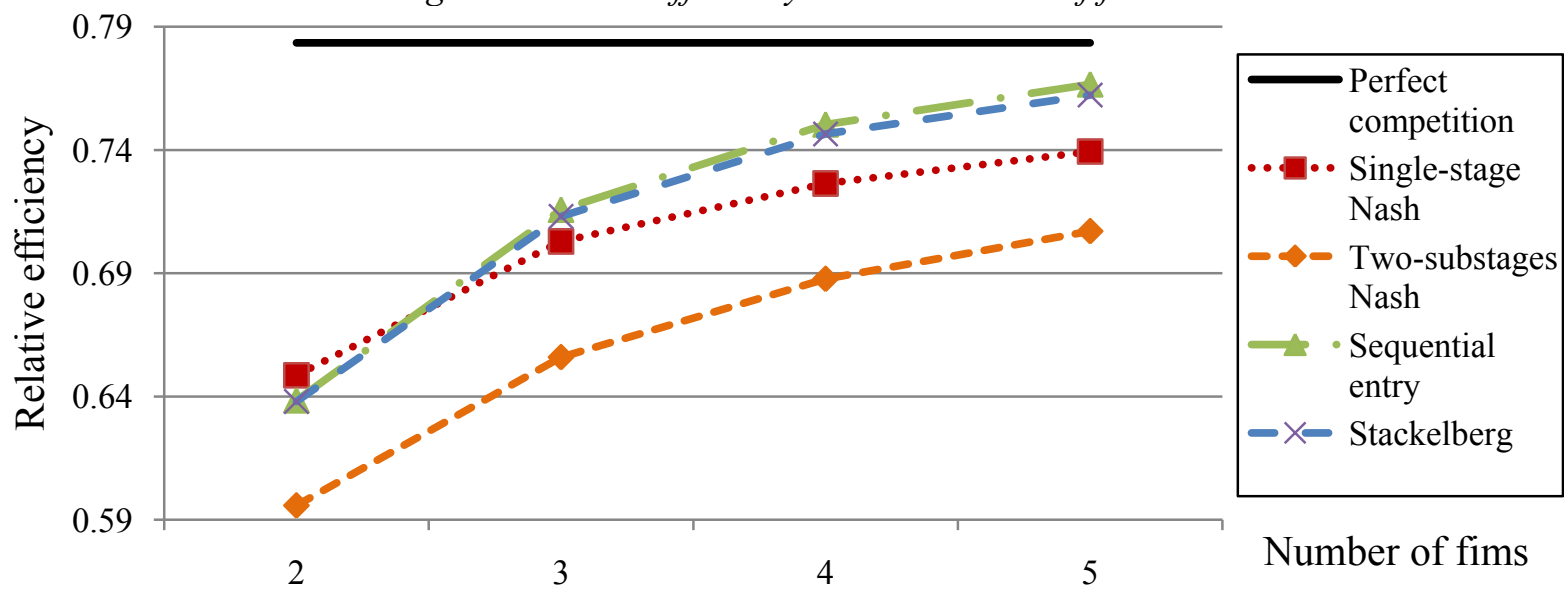

It is important to perform sensitivity analyses to important parameters. We focus on the effect of the amount of initial capacity. The effects of other such standard things as price elasticity and value of time are as one would expect: e.g. more price sensitive demand makes private provision more beneficial, as it limits market power. With more initial capacity, the gain of the first-best policy is lower, since there is less to gain from the capacity expansion. For the second-best, single-firm, and perfect-competition cases the gain and relative efficiency are lower: capacity expansion is less important and there is more initial capacity that remains untolled (see also Verhoef, 2007). The oligopolistic settings also attain lower gains; but relative to perfect competition they fare better, because the larger untolled capacity limits the oligopolistic market power.

\section{Conclusion}

This paper reconsidered capacity, price, and service-quality setting of private competitors in oligopolistic markets for congestible services applied to the case of road transport. Previous studies found that, under some technical assumptions, firms competing in parallel set a volume/capacity ratio that is socially optimal if they take the actions of the others as given in a Nash fashion. We find that this single-stage Nash-competition assumption is crucial. If firms can influence the decisions of others with their capacity, this changes their capacitysetting rule, and they generally set a different ratio than the socially optimal one.

In our Stackelberg market structure, firms first set their capacities one after another and then set their tolls in a Nash fashion. Firms have two strategic considerations: (1) they want to limit the capacities of firms that follow by setting a higher capacity, and (2) they want to limit the toll competition by setting a lower capacity. The first firms to act have many capacities to influence, and hence set a higher capacity and lower volume/capacity ratio than they otherwise would. The last firms have few if any capacities to influence, and set a higher ratio.

Strategic setting of a lower capacity to limit toll competition is harmful for welfare as it lowers capacities and increases tolls. Stackelberg setting of higher capacities to limit competitors' capacities can be good or bad for welfare: it increases the market power of the leaders, but also tends to increase total capacity and to decrease the average toll. The Stackelberg oligopoly seems to approach perfect competition as the number of firms increases. In our numerical model, the Stackelberg game attains, with 2 firms, $81 \%$ of the perfectly-competitive gain; with 5 firms, this is $97 \%$. A general result is that the effect of private road supply depends on the number of competitors and on the market structure: the outcomes are different in the single-stage Nash, two-substages Nash, and Stackelberg set-ups.

The reader might wonder whether our setting with many firms competing in parallel is realistic, as it is rare to have many toll roads going to the same destination. However, if the 
number of toll road keeps increasing, which seems likely, the chance that there are multiple roads going roughly in the same direction increases. Moreover, also with different network structures, strategic capacity setting might affect the outcome. An obvious follow-up are serial markets or combined serial-and-parallel markets such as in Verhoef (2008). While such stylised networks may provide interesting insights, complementary analyses using larger, more realistic, networks may give further insights that would be relevant for applied policy: notably, for the design of auctions for the right to build and operate a private infratructure.

\section{Acknowledgements}

Financial support from ERC (AdG Grant \#246969 OPTION) is gratefully acknowledged. We thank Hugo da Silva and Marcel van Berlo for valuable suggestions.

\section{References}

Basso, L.J., Zhang, A., 2007. Congestible facility rivalry in vertical structures. Journal of Urban Economics 61(2), 218-237.

Brueckner, J.K., 2002. Airport congestion when carriers have market power. American Economic Review 92(5), 1357-1375.

Brueckner, J.K., Verhoef, E.T., 2010. Manipulable congestion tolls. Journal of Urban Economics 67(3), 315321.

Buchanan, J.M., 1956. Private ownership and usage: the road case rexamined. Southern Economic Journal 22, 305-316.

Daniel, J.I., 1995. Congestion pricing and capacity of large hub airports: A bottleneck model with stochastic queues. Econometrica 63(2), 327-370.

De Borger, B., Van Dender, K., 2006. Prices, capacities and service quality in a congestible Bertrand duopoly. Journal of Urban Economics 60(2), 264-283.

De Palma, A, Lindsey, R., 2000. Private roads: competition under various ownership regimes. Annals of Regional Science 34(1), 13-35.

DeVany, A.S., Saving T.R., 1980. Competition and highway pricing for stochastic traffic. Journal of Business 53(1), 45-60.

Edelson, N.M., 1971. Congestion tolls under monopoly. American Economic Review 61(5), 873-882.

Engel, E., Fisher, R., Galetovic, A., 2004. Toll Competition among Congested Roads. Topics in Economic Analysis \& Policy 4, Article 4.

Knight, F.H., 1924. Some fallacies in the interpretation of social cost. Quarterly Journal of Economics 38(4), 582-606.

Lévy-Lambert, H., 1968. Tarification des services à qualité variable: application aux Péages de Circulation. Econometrica 36(3-4), 564-574.

Marchand, M., 1968. A note on optimal tolls in an imperfect environment. Econometrica 36(3-4), 575-581.

Mohring, H., 1985. Profit maximization, cost minimization, and pricing for congestion-prone facilities. Logistics and Transportation Review 21, 27-36.

Mohring, H., Harwitz, M., 1962. Highway benefits: an analytical framework. Northwestern University Press, Evanston, IL.

Small, K.A., Verhoef, E.T., 2007. The Economics of Urban Transportation. Routledge, London.

Tan, Z., Yang, H., Guo, X., 2010. Properties of Pareto-efficient contracts and regulations for road franchising. Transportation Research Part B 44(4), 415-433.

Verhoef, E.T., 2007. Second-best road pricing through highway franchising. Journal of Urban Economics 62(2), 337-361.

Verhoef, E.T., 2008. Private roads: auctions and competition in networks. Journal of Transport Economics and Policy 42(3), 463-493.

Washington State Department of Transport, 2005. Highway construction costs: are WSDOT's highway construction costs in line with national experience? (version of 3 November 2005). Retrieved on 25 March 2011, from www.wsdot.wa.gov/biz/construction/CostIndex/pdf/HighwayConstructionCosts2005.pdf

Wu, D., Yin, Y., Yang, H., 2011. The independence of volume-capacity ratio of private toll roads in general networks. Transportation Research Part B 41(1), 96-101.

Xiao, F., Yang, H., Han, D., 2007. Competition and efficiency of private toll roads. Transportation Research Part B 41(3), 292-308.

Zhang, A., Zhang, Y., 2006. Airport capacity and congestion when carriers have market power. Journal of Urban Economics 60(2), 229-247. 